\title{
Aesthetic Rehabilitation with Ocular Prosthesis - A Case Report
}

\author{
Rajesh Khan $^{1}$, Shubhabrata Roy ${ }^{2}$ \\ ${ }^{1}$ Faculty, Department of Prosthodontics and Crown \& Bridge, Dr. R. Ahmed Dental College \& Hospital, \\ Kolkata. \\ ${ }^{2}$ Faculty, Department of Prosthodontics and Crown \& Bridge, Gurunanak Institute of Dental Science and \\ Research, Kolkata.
}

Corresponding Author: Rajesh Khan

\begin{abstract}
It is obvious that a person suffers from severe emotional, social, and psychological trauma when an eye is lost due to any reason. After evisceration, custom made ocular prosthesis can be used to improve facial aesthetics as well as social representation of that person. It is always a challenge to properly fabricate an alternate to the lost eye. But after fabrication, it certainly improves psychological satisfaction of the patient. In this case report, it is attempted to show how a patient was aesthetically rehabilitated with an ocular prosthesis.
\end{abstract}

Key Words: Ocular prosthesis, Ocular conformer, Scleral shell

\section{INTRODUCTION}

The human eye is the organ responsible for our vision and it helps us to learn more about the surrounding world than we do with any of the other four senses. Facial aesthetics largely depends on the eyes. Loss of an eye may have a tremendous functional, emotional, social and psychological impact on a person ${ }^{[1]}$. Functional rehabilitation of a lost eye is still a subject of research. But one can provide an ocular prosthesis to aesthetically rehabilitate a patient.

\section{CASE REPORT}

A 46 year old male patient reported to the Department of Prosthodontics and Crown \& Bridge with history of evisceration of right eye. His right eye was severely damaged due to trauma nearly two and half months ago. After hospitalization, evisceration of that eye was performed by surgeon (Fig 1). He was psychologically very upset because of the unprecedented traumatic event. It was decided to fabricate an ocular prosthesis for him as soon as possible. His upper and lower eyelids and extra-ocular muscles were intact and functional. An ocular conformer was made in clear acrylic resin with the help of a spoon (Fig 2). Multiple holes were made in the conformer to provide mechanical retention for the impression material. At the centre of the conformer a comparatively larger hole was made to attach a $5 \mathrm{ml}$ injection syringe (Fig 3). After disinfection, the conformer along with a syringe was checked in patient's eye (Fig 4). Impression was made in polyvinyl siloxane (light body consistency) (Fig 5, 6, and 7). The impression was poured in stone and a cast was obtained (Fig 8). After applying coldmould-seal (separating media), a thin scleral shell was made with tooth-coloured cold cure acrylic resin (Fig 9). The shell was placed inside the patient's eye and position of pupil was marked (fig 10). The diameter of pupil of the other eye (left eye) was measured and a small disc of clear acrylic resin with same diameter was fabricated. 
The disc was painted with acrylic colour to simulate the natural look of the other pupil. The disc was positioned properly on the acrylic shell and base-plate wax was used to properly contour the prosthesis ${ }^{[2]}$. The wax pattern was checked on patient (Fig 11). A small wire was fixed on the pupil as position indicator (Fig 12) and the wax pattern was then flasked. After dewaxing, packing was done with tooth-coloured heat cure acrylic

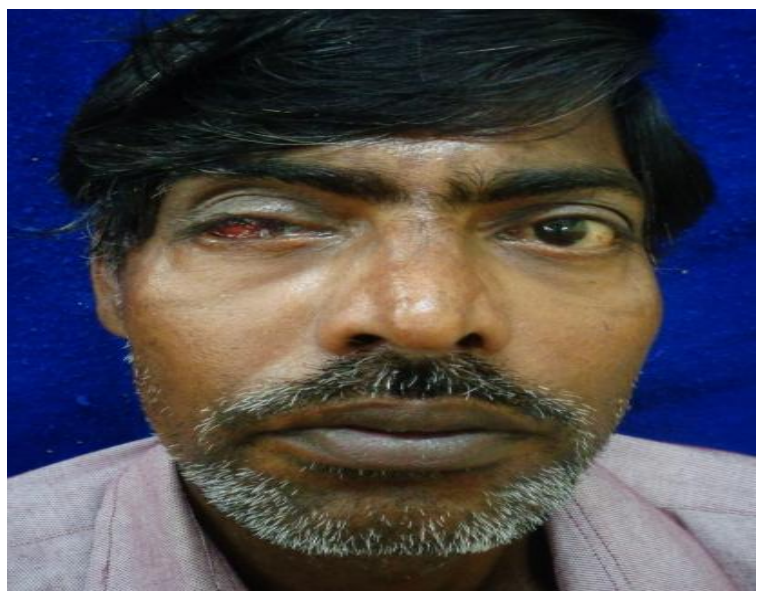

Figure 1

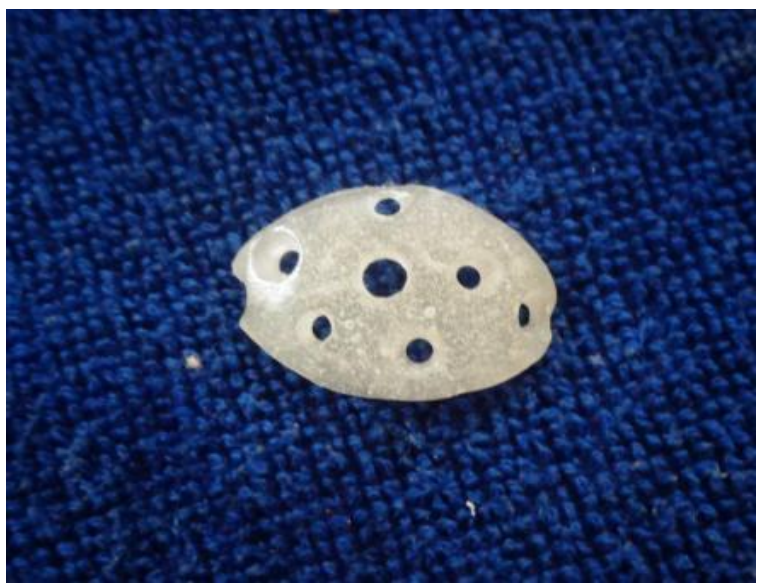

Figure 2

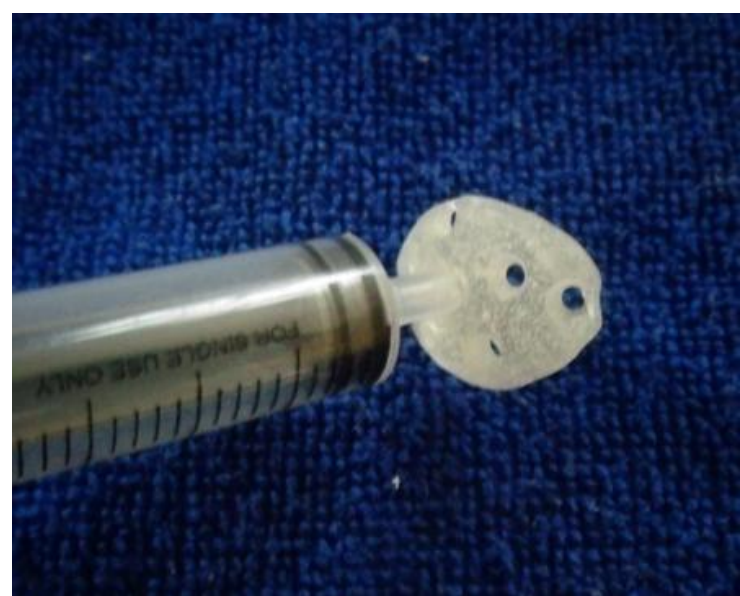

Figure 3 resin. After curing and bench cooling, the prosthesis was retrieved. After final characterization, finishing and polishing were done (Fig 13). After placement, final prosthesis was compared with the other side normal eye (Fig 14\& 15). Although nothing can replace his lost eye, still the ocular prosthesis increased confidence of the patient significantly (Fig 16).

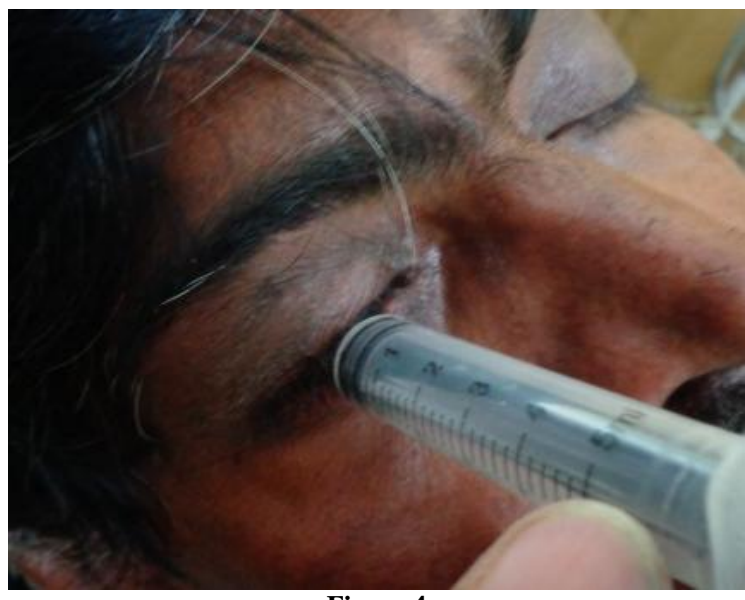

Figure 4

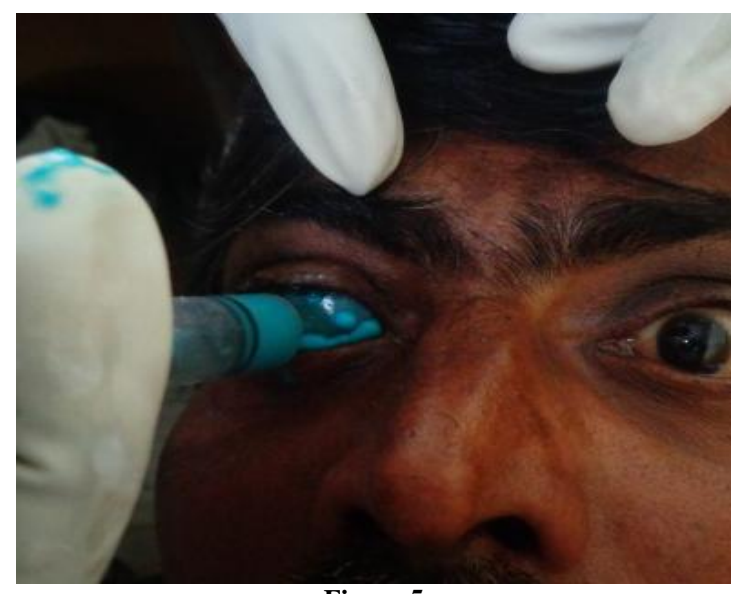

Figure 5

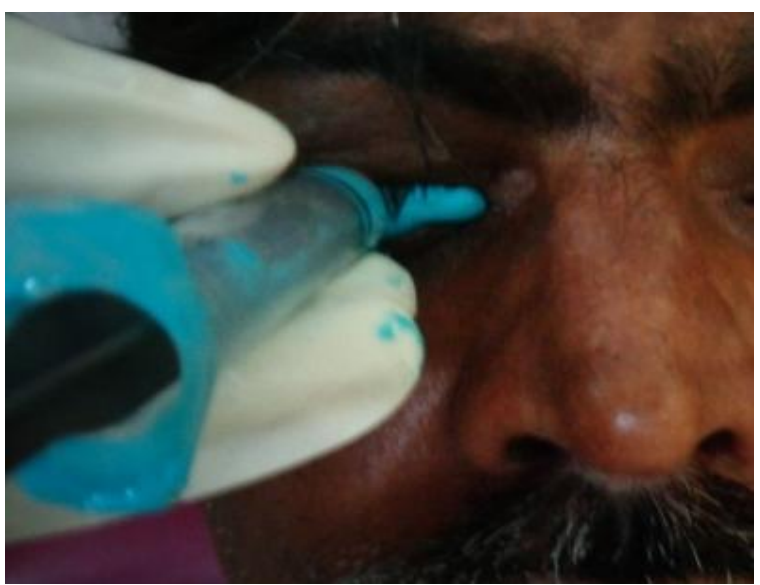

Figure 6 


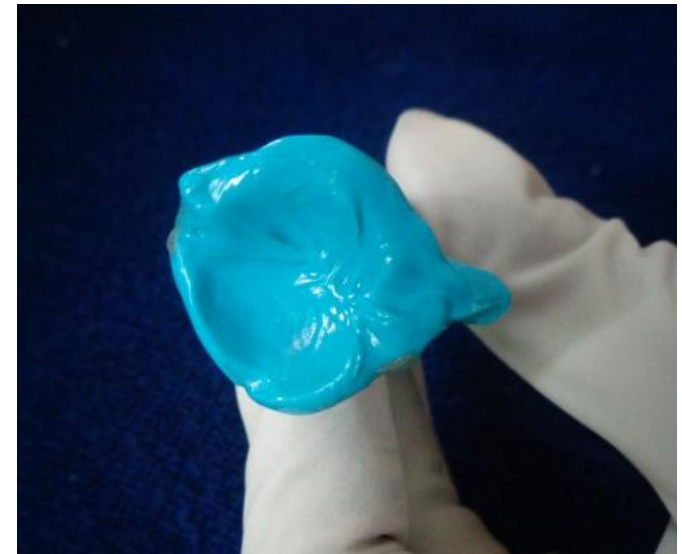

Figure 7

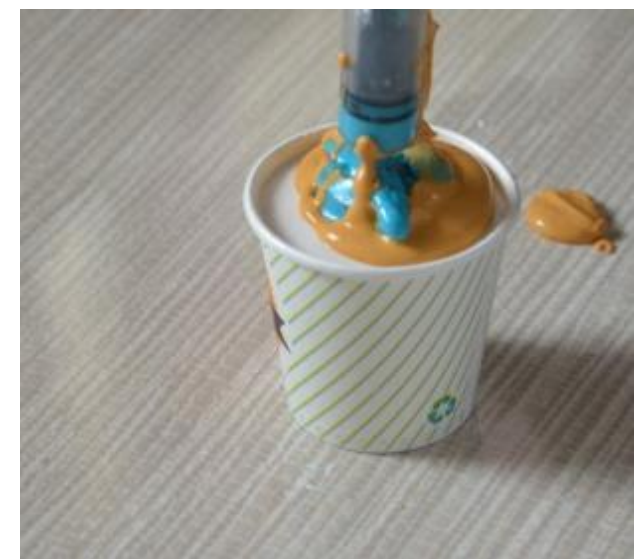

Figure 8

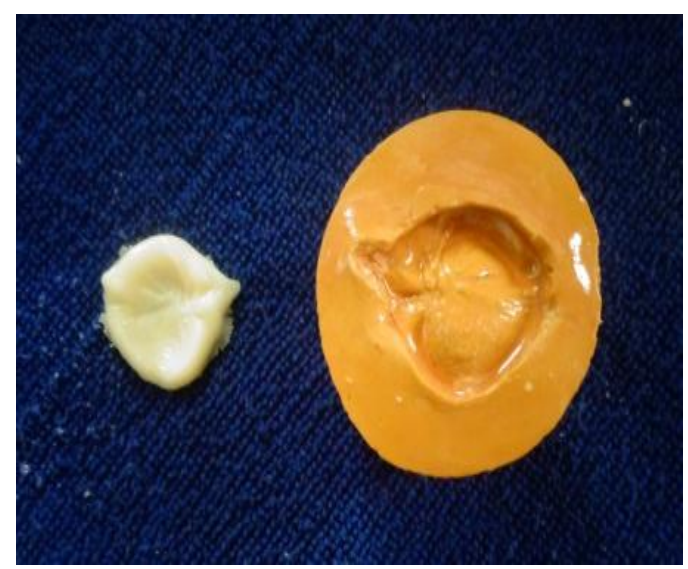

Figure 9

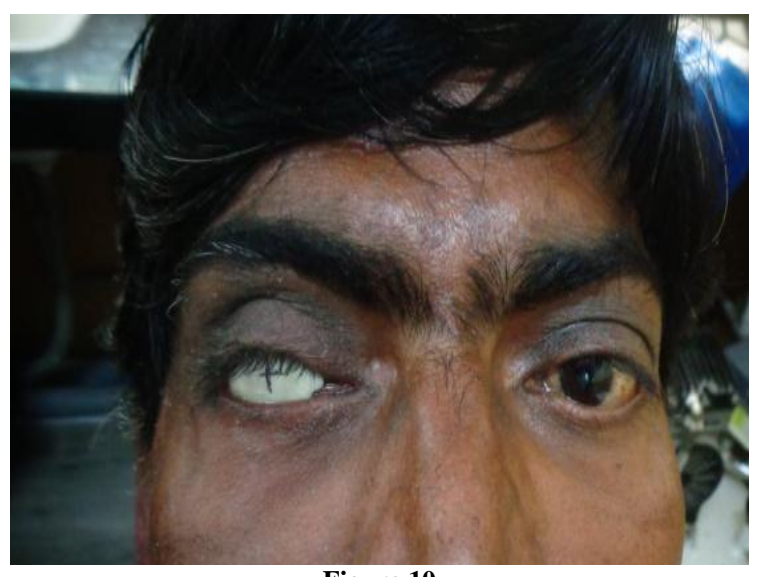

Figure 10

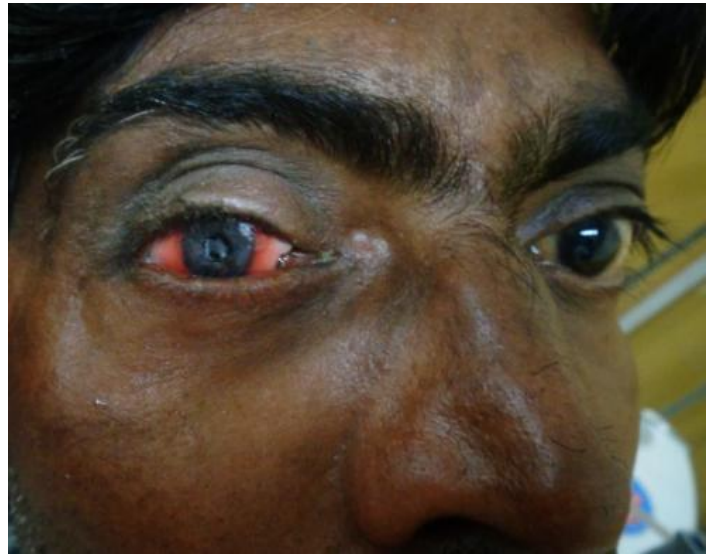

Figure 11

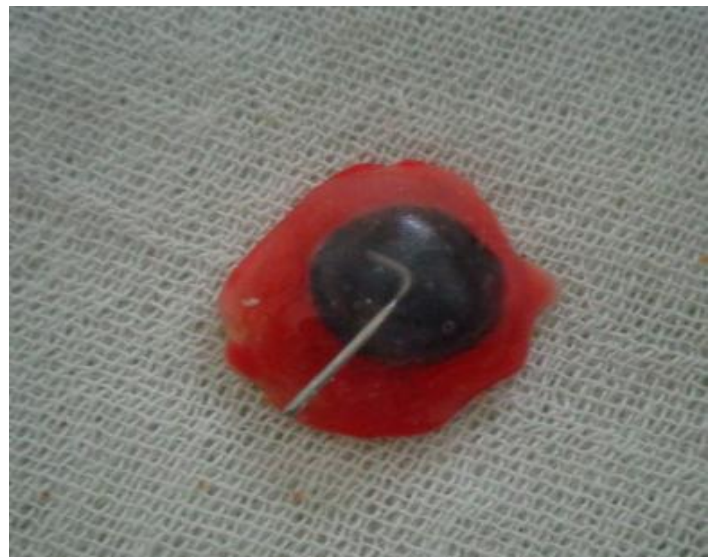

Figure 12

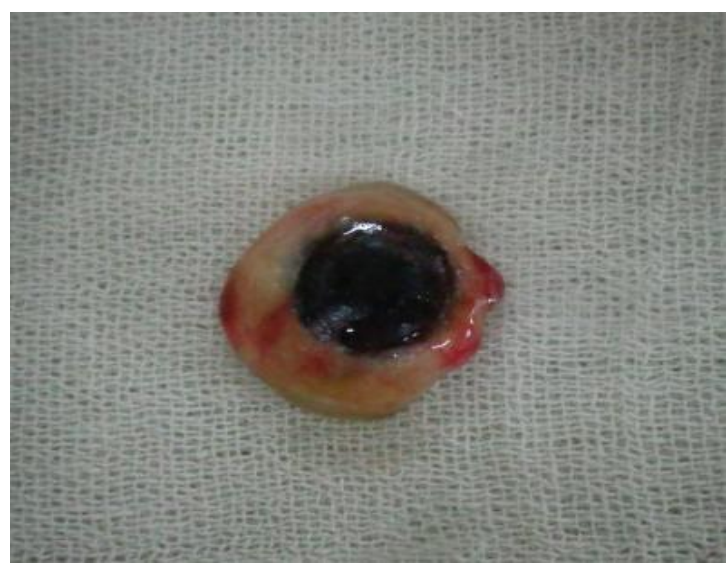

Figure 13

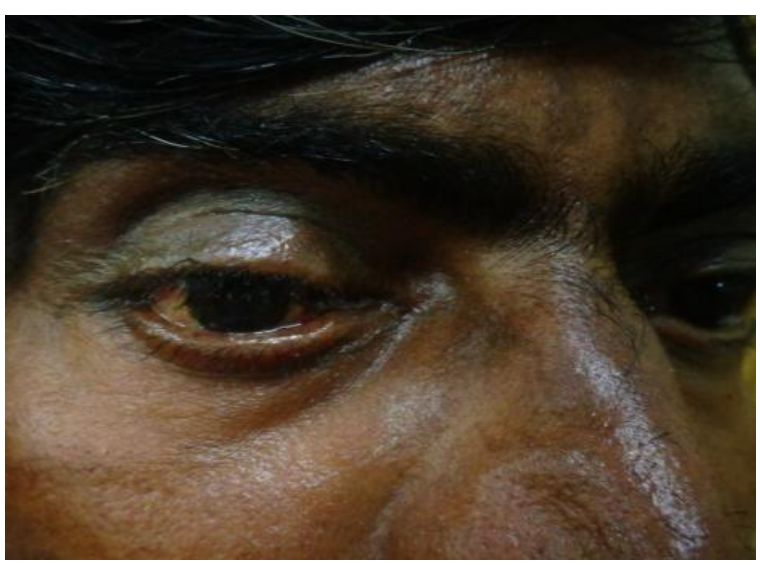

Figure 14 


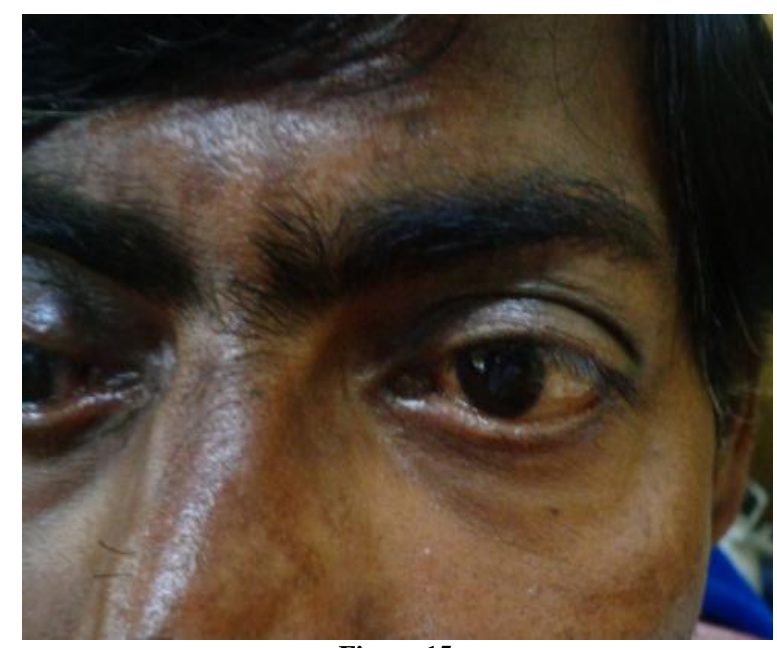

Figure 15

\section{DISCUSSION}

Evisceration is a surgical technique by which all intraocular contents are removed while preserving the remaining scleral shell, extraocular muscle attachments, and surrounding orbital adnexa ${ }^{[3]}$. After evisceration, an ocular prosthesis can be used to at least aesthetically rehabilitate a patient. The custom-made acrylic resin ocular prosthesis achieves intimate contact with the tissue bed ${ }^{[4]}$. This close adaptation tends to distribute pressure more uniformly than does stock eye prosthesis ${ }^{[5]}$. Thus the incidence of conjunctival abrasion is diminished. Tissue health is further enhanced by reducing potential stagnation spaces at the prosthetictissue interface ${ }^{[6]}$. Fluid collection in the space could cause tissue irritation and enhance bacterial growth [7]. Proper fit, optimum retention and acceptable look of the prosthesis, along with simulation of eye movements certainly provide psychological comfort and satisfaction to the patient ${ }^{[8]}$.

\section{Acknowledgement: None}

\section{Conflict of Interest: None}

\section{Source of Funding: None}

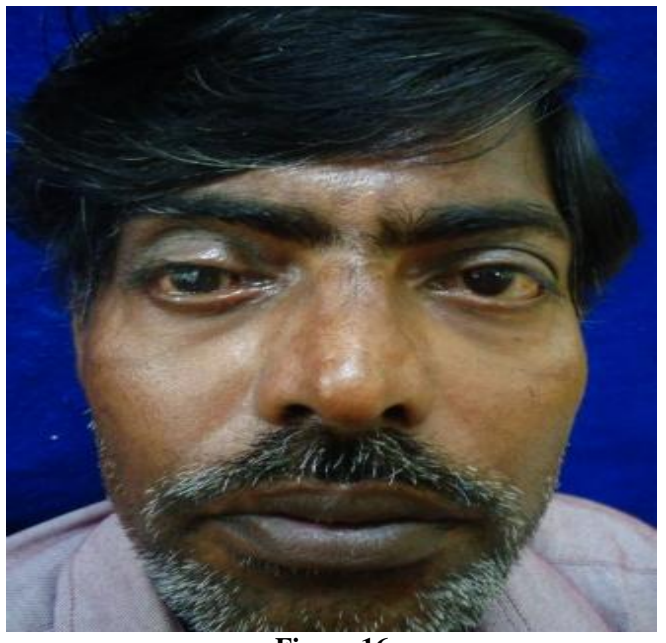

Figure 16

\section{REFERENCES}

1. Banerjee S, Kumar S, Pal D, Biswas D, Giri TK. Custom made ocular prosthesis -A case report. Clinical Dentistry (0974-3979). Oct2014, Vol. 8 Issue 10, p9-13. 5p.

2. Guttal SS, Patil NP, Vernekar N, et al: A simple method of positioning the iris disk on a custom-made ocular prosthesis. A clinical report. J Prosthodont 2008;17:223227

3. http://eyewiki.aao.org/Evisceration. As retrieved on 13.3.2017

4. Benson P. The fitting and fabrication of a custom resin artificial eye. J Prosthet Dent 1977; 38:532

5. Cain JR. Custom ocular prosthetics. J Prosthet Dent 1982;48:690,1982

6. Beumer J, Curtis TA, Marunick MT: Maxillofacial Rehabilitation: Prosthodontic and Surgical Considerations. St. Louis, Ishiyaku Euro America, St. Louis, 1996, pp. 417-431

7. Taylor TD. Clinical maxillofacial prosthetics. Chicago: Quintessence Publishing; 2000. p. 265-276.

8. Prasad K, Prasad A, Alva H. Fabrication Of Customised Esthetic Acrylic Ocular Prosthesis. Guident. Prosthodontics. Jul2013, Vol. 6 Issue 8, p10-14.

How to cite this article: Khan R, Roy S. Aesthetic rehabilitation with ocular prosthesis a case report. Int J Health Sci Res. 2021; 11(8): 190-193. DOI: https://doi.org/10.52403/ijhsr. 20210827 